\title{
Cmambu
}

\section{УСТАНОВКИ ПРИВЕРЖЕННОСТИ МАСОЧНОМУ РЕЖИМУ РОССИЙСКИХ РЕСПОНДЕНТОВ В ПЕРИОД ПАНДЕМИИ COVID-19}

\author{
М.А. ПАДУН ${ }^{\text {, С.С. БЕЛОВА }}{ }^{\text {a }}$ Т.А. НЕСТИК ${ }^{\mathrm{a}}$ \\ ${ }^{a}$ ФГБУН Институт психологии РАН, 129366, Москва, ул. Ярославская, д. 13, к. 1
}

\section{Adherence Attitudes towards Mask Wearing Regulations in Russia during COVID-19 Pandemic}

\author{
M.A. Padun ${ }^{\text {a }}$ S.S. Belova ${ }^{\text {a }}$, T.A. Nestik ${ }^{a}$
}

${ }^{a}$ Institute of Psychology, Russian Academy of Sciences, 13 build. 1, Yaroslavskaya Str., Moscow, 129366, Russian Federation

\section{Резюме}

Статья представляет эмпирическое исследование установок российских респондентов в отношении масочного режима в начале второй волны пандемии COVID-19 (октябрь 2020 г.; $\mathrm{N}=884$ ). Представлен оригинальный опросник из 7 шкал установок приверженности, определяющих следование масочному режиму. Структура установок наилучшим образом описывалась иерархической моделью с общим фактором установки приверженности, тремя факторами установок второго порядка в отношении «дискомфорта в связи с масками», «угрозы COVID-19 для себя и других», «рациональной оценки пандемии COVID-19», 7 факторами частных

\begin{abstract}
The paper presents an empirical study of adherence attitudes to wearing face masks during the second wave of COVID-19 pandemic in Russia (October 2020, N=884). The new questionnaire on adherence attitudes to wearing face masks is presented. It consists of 7 scales of attitudes, which determine adherence to mask wearing regulations. The structure of attitudes was described by a hierarchical model with a general factor of adherence attitude, three second-order factors with respect to the "discomfort related to face coverings", "perceived threat of COVID-19 for oneself and others", "rational assessment of COVID-19
\end{abstract}

Статья подготовлена в соответствии с госзаданиями Министерства образования и науки РФ № 0138-2021-0005 (М.А. Падун); № 0138-2021-0009 (С.С. Белова); № 0138-2021-0010 (Т.А. Нестик).

The research was carried out within the state assignment of Ministry of Science and Higher Education of the Russian Federation (themes NN 0138-2021-0005 (M.A. Padun), 0138-2021-0009 (S.S. Belova), 0138-2021-0010 (T.A. Nestik)). 
установок по опроснику. Их составили: 1) просоциальность; 2) толерантность к физическому дискомфорту; 3) страх за себя и близких; 4) антиконспирологическая установка в отношении COVID-19; 5) комфортность общения в маске; 6) принятие ограничений индивидуальной свободы; 7) устойчивость самооценки. Выявлено, что частные установки значимо дифференцировали группы респондентов, различавшихся соблюдением масочного режима и мотивами его неустойчивого соблюдения. Описаны социально-демографические различия в установках и приверженности масочному режиму. Показано, что на уровне установок мужчины менее ориентированы на соблюдение масочного режима: в сравнении с женщинами они менее просоциальны, ассоциируют ношение масок с проявлением слабости, приуменьшают угрозу COVID-19 для себя и близких, менее толерантны к физическому дискомфорту в связи с масками. В заключение обсуждается проблема одномерности самоотчетов об установках приверженности режиму ношения масок. Делается вывод о центральной роли просоциальности как установки на необходимость заботы о здоровье других людей. Обозначаются направления для разработки практических рекомендаций по поддержке приверженности ограничительным мерам при COVID-19 для отдельных групп респондентов.

Ключевые слова: COVID-19, масочный режим, установки, приверженность, ограничительные меры.

Падун Мария Анатольевна - старший научный сотрудник, лаборатория психологии развития субъекта в нормальных и посттравматических состояниях, ФГБУН «Институт психологии Российской академии наук», кандидат психологических наук.

Сфера научных интересов: клиническая психология, регуляция эмоций, психология посттравматического стресса, биопсихосоциальные модели психических расстройств.

Контакты: padunma@ipran.ru pandemic", and 7 factors of specific attitudes according to the questionnaire. The latter were 1) prosociality, 2) tolerance to physical discomfort caused by masks, 3 ) fear for oneself and friends and relatives, 4) COVID-19 anti-conspiracy beliefs, 5) comfort of communication while wearing a mask, 6 ) acceptance of restrictions of individual freedom, 7) stability of self-esteem. The specific attitudes significantly differentiated groups of participants, which differed in their adherence to mask wearing regulations and in their motivation for inconsistent adherence. Sociodemographic differences in attitudes and adherence to mask wearing regulations are described. It was revealed that on the attitudinal level, men were less oriented towards adherence to mask regime. Compared to women, they expressed less prosociality and less tolerance to physical discomfort caused by masks, associated wearing masks with manifestation of weakness, underestimated COVID-19 threat for themselves and for their relatives and friends. In conclusion, the issue of unidimensionality of self-reports of adherence attitudes is discussed. We sum up that prosocialilty as an attitude towards necessity to care about health of other people plays the central role in the adherence attitudes structure. Directions for elaboration of practical guidelines to sustain adherence to restricting regulations during COVID-19 pandemic for different groups of participants are outlined.

Keywords: COVID-19, mask wearing regulations, attitudes, adherence, restrictive measures.

Maria A. Padun - Senior Research Fellow, Institute of Psychology, Russian Academy of Sciences, PhD in Psychology.

Research Area: clinical psychology, emotion regulation, posttraumatic stress, biopsychosocial models of mental disorders.

E-mail: padunma@ipran.ru 
Белова Софья Сергеевна - научный сотрудник, лаборатория психологии и психофизиологии творчества, ФГБУН «Институт психологии Российской академии наук», кандидат психологических наук.

Сфера научных интересов: социальное познание, приверженность лечению, психология способностей.

Контакты: belovass@ipran.ru

Нестик Тимофей Александрович - заведующий лабораторией, лаборатория социальной и экономической психологии ФГБУН «Институт психологии Российской академии наук», доктор психологических наук, профессор РАН.

Сфера научных интересов: психология глобальных рисков, отношение личности к новым технологиям, групповая рефлексивность, социальный оптимизм, социальная психология временной перспективы.

Контакты: nestikta@ipran.ru
Sofya S. Belova - Research Fellow, Institute of Psychology, Russian Academy of Sciences, PhD in Psychology.

Research Area: social cognition, treatment adherence, psychology of abilities.

E-mail: belovass@ipran.ru

Timofei A. Nestik - Head of Laboratory, Institute of Psychology, Russian Academy of Sciences, DSc in Psychology, Professor of the Russian Academy of Sciences.

Research Area: psychology of global risks, attitudes to new technologies, group reflexivity, social psychology of time perspective, social optimism.

E-mail: nestikta@ipran.ru

\section{Введение}

Данная статья представляет эмпирическое исследование, проведенное методом интернет-опроса в начале второй волны пандемии COVID-19 (октябрь 2020 г.), по изучению установок россиян в отношении соблюдения масочного режима.

Как показывают данные зарубежных опросов, даже при учете национальной специфики, доля людей, выражающих неприятие этой ограничительной меры в истории пандемии COVID-19, является сравнительно небольшой, но стабильной - порядка 15-20\% (Taylor, Asmundson, 2021). Поляризация мнений ведет к росту психологической напряженности, что находит отражение в острых социальных и политизированных дискуссиях в СМИ, интернет-пространстве и на бытовом уровне (Scerri, Grech, 2020). При этом опыт моделирования динамики эпидемии COVID-19 свидетельствует о том, что отказ почти пятой части населения следовать данной ограничительной мере оказывает существенный негативный эффект на темп распространения инфекции (Eikenberry et al., 2020).

В юридической психологии следование ограничениям объясняется инструментальными и нормативными моделями (Tyler, 2006). Согласно инструментальным моделям, люди действуют рационально для максимизации персональной выгоды и минимизации потерь. Это означает, что они демонстрируют приверженность ограничительным мерам, стараясь избежать рисков, связанных с соответствующими санкциями органов власти, а также с опасностью заражения как такового. Вместе с тем показано, что санкции сами по себе не гарантируют приверженность (Pratt et al., 2008). Лишь в некоторой 
степени соблюдение правил может быть усилено повышением вероятности «быть пойманным» (Nagin, 2013), что, однако, не всегда возможно на практике. Опасность же заражения может рассматриваться как ничтожная теми, кто не входит в группы риска.

Нормативные модели объясняют следование ограничениям интернализованными нормами, т.е. убеждениями в том, что соблюдать законы - хорошо и правильно. Они являются предиктором приверженности даже при контроле представлений о риске наказания (Murphy et al., 2016) и в значительной мере связаны с доверием государственным структурам (Goldsmith, 2005). В период пандемии доверие органам власти в России было низким (Нестик и др., 2020), следовательно, анализ демографических и индивидуально-психологических факторов приверженности приобретает особое значение. В этой плоскости задана цель настоящей работы.

Известно, что в период пандемии респираторных вирусных инфекций женщины и пожилые люди в большей степени привержены выполнению рекомендаций по сохранению здоровья (Bish, Michie, 2010). Это объясняется более высоким уровнем воспринимаемой уязвимости у женщин, т.е. более высокой оценкой ими рисков заболевания; увеличением значимости проблемы здоровья с возрастом (Там же). Данные о связи уровня образования и приверженности не однозначны, хотя данные о позитивной связи скорее доминируют (Bish, Michie, 2010; Taylor, Asmundson, 2021). Это свидетельствует о важности учета дополнительных ситуационных переменных и индивидуальнопсихологических факторов. Среди последних мы предлагаем обратиться к установочным детерминантам поведения, которые определяются субъективным отношением к различным аспектам режима ношения масок. Насколько нам известно, дифференцированная картина подобных установок, описывающая их содержание и мерность, до сих пор не изучалась. Вместе с тем их вклад в приверженность ограничениям в условиях пандемии COVID-19 целесообразно изучить и описать для того, чтобы наметить пути поддержания ее оптимального уровня.

Исходная позиция нашего подхода заключается в том, что следование режиму ношения масок будет определяться индивидуальными установками, которые отражают субъективное переживание данного ограничения индивидом через призму его психологических потребностей. Современные взгляды на психологические потребности связывают потребности с мотивами и переживаниями, которые, в свою очередь, детерминируют поведение (Prentice et al., 2014). В целом психологические теории сходятся на выделении главных видов потребностей: в безопасности, получении удовольствия, близости с другими людьми, самоуважении, автономии, компетентности (Фрейд, 2018; Маслоу, 2008; Ryan, Deci, 2000).

Любые ограничительные меры создают ситуацию фрустрации потребностей, интенсивность которой зависит от того смысла, который люди в эти потребности вкладывают. Индивидуальное значение события (в данном случае - ограничительных мер) формирует представление (установку) в отношении самого события или отдельных его аспектов. Рассмотрим подробнее 
установки, предположительно связанные с приверженностью режиму ношения масок.

Ситуация пандемии фрустрирует базовые потребности в безопасности. Страх заболевания и его рисков выступает базовым предиктором приверженности ношению масок. Показано, что на начальном этапе пандемии COVID19 именно страх (но не политические и моральные убеждения) предсказывал приверженность ограничительным мерам (социальное дистанцирование, гигиена рук) (март 2020 г., Великобритания; Harper at el., 2021). При этом искаженное представление об угрозе COVID-19 в виде конспирологических теорий подрывало соблюдение масочного режима, причем было предсказательным в долгосрочной перспективе - от марта к июню 2020 г. (данные США; Romer, Jamieson, 2020).

Потребность испьтывать удовольствие также ущемляется при ношении масок. Особое место среди дискомфортных состояний занимает головная боль. Наиболее часто от нее страдают лица, которые носят одновременно маску и защитные очки более 4 часов в день, а также страдали головной болью paнеe (Ong et al., 2020). Другие проблемы составляют угревая сыпь, рубцы на переносице, повышение температуры лица, зуд и раздражение кожи (Scheid et al., 2020). Вместе с тем, у относительно здоровых людей даже продолжительное ношение респираторов типа N95 не ведет к клинически значимым изменениям в концентрации кислорода и углекислого газа в крови, а также не влияет на объем и частоту дыхания (Roberge et al., 2010b). Тем не менее имеет место выраженное напряжение мышц, вовлеченных в процесс дыхания, связанное с увеличением сопротивления дыханию при ношении маски (Roberge et al., 2010a). Обсуждается, что одноразовые медицинские маски в этом отношении являются более щадящими (Scheid et al., 2020). На феноменологическом уровне происходит формирование установки толерантности к дискомфорту или же, наоборот, нетерпимости к нему.

Потребность быть связанным с другими людьми переживается через чувство принадлежности к группе, а также через процессы коммуникации. Так, просоциальная установка, связанная с переживанием ценности жизни и здоровья других, групповой солидарности, повышает приверженность режиму ношения масок. Известно, что в случае эпидемии COVID-19 ношение маски защищает других в гораздо большей степени, чем самого человека. Приверженность может усиливаться и идентификацией с группой тех или иных убеждений и взглядов. Например, на ранней стадии пандемии в США лица, поддерживающие демократов или республиканцев, в разной степени соблюдали масочный режим (поддерживающие демократов демонстрировали бо́льшую приверженность, чем поддерживающие республиканцев) (Ibid.). Известно, что групповая идентификация, сопереживание и представления о том, как будут вести себя другие люди, оказывают влияние на соблюдение санитарно-эпидемиологических норм (Martínez et al., 2021; Pfattheicher et al., 2020). С другой стороны, маски ограничивают возможности выражения и распознавания эмоций в общении, что может выступать препятствием приверженности их ношению. 
Потребность в поддержании самоуважения также может быть фрустрирована масочным режимом. По опыту предыдущих эпидемий известно, что мужчины реже женщин носят маски (Lau et al., 2010; Tang, Wong, 2004). В частности, это связывается с их негативными чувствами по поводу того, что ношение масок постыдно и является проявлением слабости (Capraro, Barcelo, 2020).

Согласно теории самодетерминации (Ryan, Deci, 2000), люди имеют потребность в автономии и, соответственно, имеют низкую мотивацию к действиям, причина которых лежит вовне. Показано, что психологическое сопротивление как черта, выражающаяся в склонности к чрезмерным негативным эмоциональным реакциям в ответ на внешние распорядки и правила, ограничивающие индивидуальную свободу (Rosenberg, Siegel, 2018), препятствует приверженности масочному режиму во время пандемии COVID-19 (Taylor, Asmundson, 2021). Феномен подобного сопротивления ущемлению гражданских свобод наблюдался и при пандемии испанского гриппа 1918-1920 гг. (Scerri, Grech, 2020). Вместе с тем люди различаются по выраженности сопротивления внешним ограничениям.

Потребность в компетентности при ношении масок проявляется в стремлении человека понимать обоснованность этой ограничительной меры, а именно быть осведомленным и доверять информации об эффективности масок для снижения распространения инфекции и быть убежденным в их безопасности для здоровья. В целом научные данные свидетельствуют о том, что риски, связанные с COVID-19, значительно превышают риски, связанные с ношением масок (Scheid et al., 2020; Roberge et al., 2010a; Roberge et al., 2010b). Ношение медицинских одноразовых масок и их аналогов, наряду с мерами социального дистанцирования и защиты глаз, связано с существенным снижением риска инфицирования вирусами SARS-CoV-2, SARS-CoV и MERS$\mathrm{CoV}$ (Chu et al., 2020). Тем не менее субъективное доверие подобной информации вариативно, а очевидный дискомфорт при ношении масок способствует росту сомнений в их безопасности.

Таким образом, спектр психологических установок и их полюсов, потенциально связанных с приверженностью масочному режиму, широк. Мы поставили исследовательский вопрос: каково соотношение психологических установок, связанных со сферой данных потребностей, у лиц, демонстрирующих разную степень приверженности масочному режиму? Проверялась гипотеза о том, что данный набор установок, отражающих представления о самом себе, других людях, а также о пандемии COVID-19, будет дифференцировать лиц с устойчивой приверженностью, неустойчивой приверженностью и неприверженностью масочному режиму. При этом лица с неустойчивой приверженностью будут иметь различные установки в зависимости от мотивационных оснований, по которым они то носят, то не носят маски (гипотеза 2). Среди мотивационных оснований были выделены ориентации на ситуативную рациональность, конформизм, избегание санкций. Также были выдвинуты гипотезы о более выраженных установках приверженности у женщин, лиц пожилого возраста, лиц с высшим образованием. 


\section{Методика}

Исследование проводилось методом анонимного интернет-опроса через систему «Анкетолог» $3-4$ октября 2020 г.

Объем выборки составил 884 респондента. Средний возраст - 39.64 года (ст. откл. -10.78 , разброс $-18-73), 57.4 \%$ женщины. Образование высшее $-65.2 \%$, незаконченное высшее $-6.6 \%$, среднее специальное $-22.9 \%$, среднее $-4.9 \%$.

Большинство респондентов были жителями крупных городов: с населением более 1 млн. $-40.2 \%$, с населением от 500 тыс. до 1 млн $-16 \%$, от 250 тыс. до 500 тыс. $-14 \%$, менее 250 тыс. $-24.4 \%$. На вопрос «Перенесли ли вы заболевание COVID-19?» 64\% респондентов ответили «нет», $2.8 \%$ - «да, бессимптомно», $5.2 \%$ - «да, с симптомами, лечился дома», 0.3\% - «да, лечился в стационаре», $27.5 \%$ - «не знаю». Менее $1 \%$ респондентов сообщили о потере родных и близких людей из-за COVID-19.

\section{Результаты}

\section{Приверженность масочному режиму при пандемии COVID-19}

Более половины респондентов сообщили, что они всегда или почти всегда носят маски в общественных местах (57.5\%), треть (31.2\%) носят маски иногда, и десятая часть $(11.3 \%)$ - никогда. Распределение респондентов по соблюдению масочного режима не связано с их возрастом и образованием (критерий хи-квадрат, $p=0.326, p=0.627$ соответственно). Женщины в сравнении с мужчинами чаще отвечают, что носят маски «всегда или почти всегда», и реже - что «иногда» и «никогда» (критерий хи-квадрат с поправкой на непрерывность, односторонний р-уровень для направленных гипотез 0.00, 0.01, 0.01 соответственно).

\section{Структура опросника установок в отношении масочного режима при пандемии COVID-19}

На основании приведенного выше теоретического анализа были выделены следующие значимые для приверженности ношению масок установки:

(1) просоциальность (забота о здоровье других);

(2) толерантность к физическому дискомфорту (представление о том, что неприятные физические ощущения от масок можно потерпеть);

(3) страх за себя и близких;

(4) конспирологическая установка - убеждение в искусственном происхождении COVID-19;

(5) дискомфорт в общении (представления о неудобстве масок в коммуникации: сложности в понимании другого человека и в распознавании его эмоций);

(6) ориентация на индивидуальную свободу (представление о том, что власти не имеют права ограничивать человека в его выборе);

(7) дискомфорт в сфере самооценки. 
Двумя первыми авторами статьи был разработан опросник из 26 пунктов, предположительно релевантных 7 субшкалам установок в отношении масочного режима. Соотношение пунктов с прямым и обратным ключом составило 7 к 19. К оценке качества формулировок и содержательной валидности пунктов были привлечены 4 внешних эксперта, кандидаты психологических наук, научные сотрудники ИП РАН. Предпринято редактирование формулировок с учетом замечаний экспертов.

Был проведен факторный анализ ответов на утверждения опросника (метод главных компонент с вращением Varimax; KMO $=0.949$, значимость коэффициента сферичности Бартлетта меньше 0.001). При обработке баллы пунктов с обратным ключом были инвертированы; таким образом, высокие оценки по субшкалам соответствовали выраженным установкам приверженности. В связи с этим названия ряда субшкал были изменены на противоположные (в частности, «конспирологическая установка» изменена на «антиконспирологическую установку», «ограничения индивидуальной свободы» на «принятие ограничений индивидуальной свободы», «дискомфорт в общении» - на «комфортность общения», дискомфорт в сфере самооценки - на «устойчивость самооценки»).

Соответственно выделено 7 факторов с нагрузками утверждений выше или равными 0.5, объяснявшие 73.2\% дисперсии: просоциальность ( $\alpha=0.853)$, толерантность к физическому дискомфорту ( $\alpha=0.857)$, страх за себя и близких $(\alpha=0.851)$, антиконспирологическая установка $(\alpha=0.838)$, комфортность общения $(\alpha=0.864)$, принятие ограничений индивидуальной свободы $(\alpha=0.858)$, устойчивость самооценки $(\alpha=0.770)$ (см. таблицу 1$)$.

Таблица 1

Факторные нагрузки пунктов опросника установок в отношении масочного режима при пандемии COVID-19 (7-факторное решение)

\begin{tabular}{|l|c|c|c|c|c|c|c|}
\hline \multicolumn{1}{|c|}{ Утверждения } & \multicolumn{5}{|c|}{ Факторы } \\
\cline { 2 - 8 } & F1 & F2 & F3 & F4 & F5 & F6 & F7 \\
\hline $\begin{array}{l}\text { Для защиты здоровья других я готов(а) носить } \\
\text { маску }\end{array}$ & $\mathbf{0 . 7 3 5}$ & 0.342 & 0.246 & 0.126 & 0.091 & 0.188 & 0.036 \\
\hline $\begin{array}{l}\text { *Я не обязан(а) носить маску, чтобы заботиться } \\
\text { о сохранении здоровья других людей }\end{array}$ & $\mathbf{0 . 6 7 6}$ & 0.234 & 0.170 & 0.131 & 0.184 & 0.347 & 0.201 \\
\hline $\begin{array}{l}\text { Я переживаю за людей, для которых коронави- } \\
\text { рус особенно опасен (люди преклонного возрас- } \\
\text { та; с хроническими заболеваниями; работа кото- } \\
\text { рых связана с непосредственными контактами) }\end{array}$ & $\mathbf{0 . 7 0 0}$ & 0.085 & 0.346 & 0.114 & 0.132 & 0.095 & 0.051 \\
\hline $\begin{array}{l}\text { *Люди не обязаны беспокоиться о здоровье дру- } \\
\text { гих и носить маски }\end{array}$ & $\mathbf{0 . 6 5 7}$ & 0.187 & 0.164 & 0.165 & 0.128 & 0.218 & 0.201 \\
\hline $\begin{array}{l}\text { *у меня есть право самостоятельно принимать } \\
\text { решение о том, носить ли маску }\end{array}$ & 0.165 & 0.073 & 0.141 & 0.178 & 0.114 & $\mathbf{0 . 8 3 1}$ & 0.080 \\
\hline $\begin{array}{l}\text { *Органы власти не должны ограничивать мою } \\
\text { свободу в принятии решения, носить ли маску }\end{array}$ & 0.242 & 0.284 & 0.185 & 0.251 & 0.086 & $\mathbf{0 . 7 0 6}$ & 0.165 \\
\hline
\end{tabular}


Таблица 1 (окончание)

\begin{tabular}{|c|c|c|c|c|c|c|c|}
\hline \multirow{2}{*}{ Утверждения } & \multicolumn{7}{|c|}{ Факторы } \\
\hline & F1 & F2 & F3 & F4 & F5 & F6 & F7 \\
\hline $\begin{array}{l}\text { *Решение о том, носить ли маску в обществен- } \\
\text { ном месте, - индивидуальное дело каждого }\end{array}$ & 0.289 & 0.248 & 0.178 & 0.223 & 0.137 & 0.720 & 0.181 \\
\hline $\begin{array}{l}\text { *Ношение маски вызывает у меня чувство } \\
\text { неполноценности }\end{array}$ & 0.340 & 0.421 & 0.037 & 0.237 & 0.300 & 0.083 & 0.481 \\
\hline $\begin{array}{l}\text { *Я воспринимаю ношение маски как проявле- } \\
\text { ние трусости }\end{array}$ & 0.492 & 0.177 & 0.243 & 0.102 & 0.142 & 0.207 & 0.566 \\
\hline $\begin{array}{l}\text { *Мне кажется, что в маске меня воспринимают } \\
\text { больным или заразным }\end{array}$ & 0.134 & 0.208 & 0.035 & 0.186 & 0.236 & 0.206 & 0.755 \\
\hline *Маска затрудняет общение между людьми & 0.160 & 0.376 & 0.104 & 0.156 & 0.705 & 0.134 & 0.252 \\
\hline $\begin{array}{l}\text { *При общении с человеком в маске трудно } \\
\text { понять, что выражает его лицо }\end{array}$ & 0.094 & 0.147 & 0.077 & 0.162 & 0.839 & 0.129 & 0.145 \\
\hline $\begin{array}{l}\text { *Маска затрудняет восприятие эмоций собесед- } \\
\text { ника }\end{array}$ & 0.163 & 0.190 & 0.099 & 0.093 & 0.860 & 0.056 & 0.050 \\
\hline $\begin{array}{l}\text { Физический дискомфорт от ношения маски } \\
\text { можно потерпеть }\end{array}$ & 0.421 & 0.673 & 0.221 & 0.130 & 0.126 & 0.163 & 0.130 \\
\hline $\begin{array}{l}\text { *Я не могу смириться с неприятными физиче- } \\
\text { скими ощущениями при ношении маски }\end{array}$ & 0.155 & 0.685 & 0.143 & 0.173 & 0.310 & 0.227 & 0.252 \\
\hline К ношению маски можно привыкнуть & 0.305 & 0.728 & 0.191 & 0.156 & 0.125 & 0.131 & 0.104 \\
\hline $\begin{array}{l}\text { *Ощущение духоты при ношении маски нестер- } \\
\text { пимо }\end{array}$ & 0.050 & 0.747 & 0.068 & 0.217 & 0.271 & 0.130 & 0.078 \\
\hline *У меня нет страха заразиться коронавирусом & 0.107 & 0.146 & 0.735 & 0.158 & 0.173 & 0.235 & 0.244 \\
\hline $\begin{array}{l}\text { Я боюсь, что я либо мои близкие заразятся } \\
\text { коронавирусом }\end{array}$ & 0.385 & 0.109 & 0.722 & 0.136 & 0.103 & 0.108 & 0.070 \\
\hline $\begin{array}{l}\text { Я испытываю тревогу, когда смотрю новости о } \\
\text { пандемии }\end{array}$ & 0.062 & 0.136 & 0.791 & 0.104 & -0.005 & 0.131 & -0.116 \\
\hline $\begin{array}{l}\text { Я испытываю/испытывал(а) бы тревогу за себя } \\
\text { и своих близких, если узнаю/узнал(а) бы, что } \\
\text { кто-то в моем окружении заболел COVID-19 }\end{array}$ & 0.451 & 0.020 & 0.643 & 0.053 & 0.076 & 0.044 & 0.037 \\
\hline $\begin{array}{l}\text { *Ситуация с коронавирусом создана определен- } \\
\text { ной группой людей в своих целях }\end{array}$ & 0.224 & 0.185 & 0.067 & 0.783 & 0.037 & 0.100 & 0.131 \\
\hline $\begin{array}{l}\text { *Паника вокруг коронавируса в СМИ намерен- } \\
\text { но раздута в интересах определенных кругов }\end{array}$ & 0.118 & 0.176 & 0.236 & 0.756 & 0.156 & 0.284 & 0.143 \\
\hline $\begin{array}{l}\text { *Кому-то выгодно, что ситуация с пандемией } \\
\text { отвлекает общество от других важных проблем }\end{array}$ & 0.104 & 0.172 & 0.090 & 0.822 & 0.237 & 0.146 & 0.006 \\
\hline $\begin{array}{l}\text { *Даже для людей, не входящих в группы риска, } \\
\text { последствия COVID-19 для здоровья могут } \\
\text { быть серьезными }\end{array}$ & 0.434 & 0.189 & 0.581 & 0.121 & 0.063 & 0.041 & 0.195 \\
\hline $\begin{array}{l}\text { *Смертность от COVID-19 не выше, чем от } \\
\text { сезонного гриппа }\end{array}$ & 0.014 & 0.091 & 0.373 & 0.505 & 0.066 & 0.283 & 0.329 \\
\hline
\end{tabular}

Примечание. Названия субшкал: F1 - просоциальность, F2 - толерантность к физическому дискомфорту, F3 - страх за себя и близких, F4 - антиконспирологическая установка, F5 - комфортность общения, F6 - принятие ограничений индивидуальной свободы, F7 - устойчивость самооценки. * Звездочкой обозначены пункты с обратным ключом. 
Выделенные факторы обнаружили высокие значимые положительные корреляции друг с другом (см. таблицу 2), в связи с чем была поставлена задача уточнить, какое описание внутренней структуры опросника будет оптимальным.

Был проведен факторный анализ субшкал опросника (метод главных компонент с вращением Varimax; KMO = 0.886, значимость коэффициента сферичности Бартлетта меньше 0.001). Выделено 3 фактора второго порядка с нагрузками шкал выше или равными 0.7, объяснявшие 79.8\% дисперсии: F01 установка в отношении дискомфорта (физический, коммуникативный дискомфорт и дискомфорт, связанный с самооценкой), F02 - установка в отношении угрозы COVID-19 (просоциальность и страх за себя и близких), F03 установка рациональности в отношении пандемии (антиконспирологическая установка и принятие ограничений индивидуальной свободы) (см. таблицу 3).

Было выявлено, что факторы второго порядка также значимо положительно коррелируют между собой. При такой картине логично предположить существование фактора более высокого порядка. В этой связи была поставлена задача оценить, какой иерархической моделью эмпирические данные могут быть описаны наилучшим образом: с наличием общего фактора установки приверженности (F0), связанным с субшкалами установок (F1-F7) непосредственно или же с опосредованием факторами установок второго порядка (F01-F03). Показатели пригодности моделей, полученные с помощью конфирматорного факторного анализа, представлены в таблице 4.

Вторая модель, в которой иерархия представлена общим фактором установки приверженности, факторами установок второго порядка и частными установками, обладала лучшими показателями соответствия (рисунок 1).

Высокие регрессионные коэффициенты показывают, что F0 как латентная переменная, отражающая общую установку приверженности масочному

Таблица 2

Матрица корреляций между субшкалами опросника установок в отношении масочного режима при пандемии COVID-19

\begin{tabular}{|l|c|c|c|c|c|c|c|}
\hline & F0 & F1 & F2 & F3 & F4 & F5 & F6 \\
\hline F1 Просоциальность & 0.813 & 1 & & & & & \\
\hline $\begin{array}{l}\text { F2 Толерантность к физическому диском- } \\
\text { форту }\end{array}$ & 0.829 & 0.636 & 1 & & & & \\
\hline F3 Страх за себя и близких & 0.702 & 0.648 & 0.483 & 1 & & & \\
\hline F4 Антиконспирологическая установка & 0.751 & 0.49 & 0.539 & 0.476 & 1 & & \\
\hline F5 Комфортность общения & 0.714 & 0.449 & 0.595 & 0.34 & 0.432 & 1 & \\
\hline $\begin{array}{l}\text { F6 Принятие ограничений индивидуаль- } \\
\text { ной свободы }\end{array}$ & 0.793 & 0.61 & 0.571 & 0.495 & 0.593 & 0.407 & 1 \\
\hline F7 Устойчивость самооценки & 0.824 & 0.645 & 0.665 & 0.457 & 0.543 & 0.584 & 0.58 \\
\hline
\end{tabular}

Примечание. Все коэффициенты корреляции значимы на уровне < 0.001. 
Таблица 3

Факторные нагрузки субшкал опросника установок в отношении масочного режима при пандемии COVID-19 (3-факторное решение)

\begin{tabular}{|l|c|c|c|}
\hline & $\begin{array}{c}\text { F01 - установка } \\
\text { в отношении } \\
\text { дискомфорта }\end{array}$ & $\begin{array}{c}\text { F02 - установка } \\
\text { отношении угрозы } \\
\text { COVID-19 }\end{array}$ & $\begin{array}{c}\text { F03 - установка } \\
\text { рациональности в } \\
\text { отношении пандемии }\end{array}$ \\
\hline F1 Просоциальность & 0.403 & 0.757 & 0.284 \\
\hline $\begin{array}{l}\text { F2 Толерантность к физиче- } \\
\text { скому дискомфорту }\end{array}$ & 0.685 & 0.383 & 0.355 \\
\hline F3 Страх за себя и близких & 0.135 & 0.879 & 0.241 \\
\hline $\begin{array}{l}\text { F4 Антиконспирологическая } \\
\text { установка }\end{array}$ & 0.261 & 0.188 & 0.863 \\
\hline F5 Комфортность общения & 0.897 & 0.103 & 0.731 \\
\hline $\begin{array}{l}\text { F6 Принятие ограничений } \\
\text { индивидуальной свободы }\end{array}$ & 0.263 & 0.388 & 0.393 \\
\hline $\begin{array}{l}\text { F7 Устойчивость } \\
\text { самоценки }\end{array}$ & 0.675 & 0.353 & 0.156 \\
\hline
\end{tabular}

Таблица 4

Показатели соответствия данным альтернативных моделей описания данных опросника установок в отношении масочного режима при пандемии COVID-19

\begin{tabular}{|l|c|c|c|c|}
\hline \multicolumn{1}{|c|}{ Модель } & CMIN/df & AGFI & RMSEA & SRMR \\
\hline $\begin{array}{l}\text { 1. Общий фактор приверженности непосред- } \\
\text { ственно связан с отдельными установками в отно- } \\
\text { шении масочного режима }\end{array}$ & 1.92 & 0.888 & 0.032 & 0.082 \\
\hline $\begin{array}{l}\text { 2. Общий фактор приверженности связан с } \\
\text { отдельными установками в отношении масочного } \\
\text { режима опосредованно, через 3 фактора второго } \\
\text { порядка }\end{array}$ & 1.92 & 0.944 & 0.032 & 0.032 \\
\hline
\end{tabular}

режиму, объясняет значительную часть факторов второго порядка. Наиболее высокий регрессионный коэффициент $(\beta=0.98)$ относится к фактору F02 (установка в отношении угрозы COVID-19 для себя и других), который, в свою очередь, в наибольшей степени $(\beta=0.96)$ объясняет фактор F1 - просоциальность.

\section{Различия в установках в отношении масочного режима при пандемии COVID-19}

\section{Социально-демографические различия}

У женщин в сравнении с мужчинами более выражены просоциальная установка, толерантность к физическому дискомфорту и устойчивость самооценки, страх за себя и близких (критерий Манна-Уитни, во всех случаях $p \leqslant 0.01$ ).

У лиц старше 60 лет в сравнении с лицами 31-45 лет более выражено принятие ограничений индивидуальной свободы (критерий Манна-Уитни, $p=0.007)$. 
Рисунок 1

Конфирматорная факторная модель опросника установок в отношении масочного режима при пандемии COVID-19

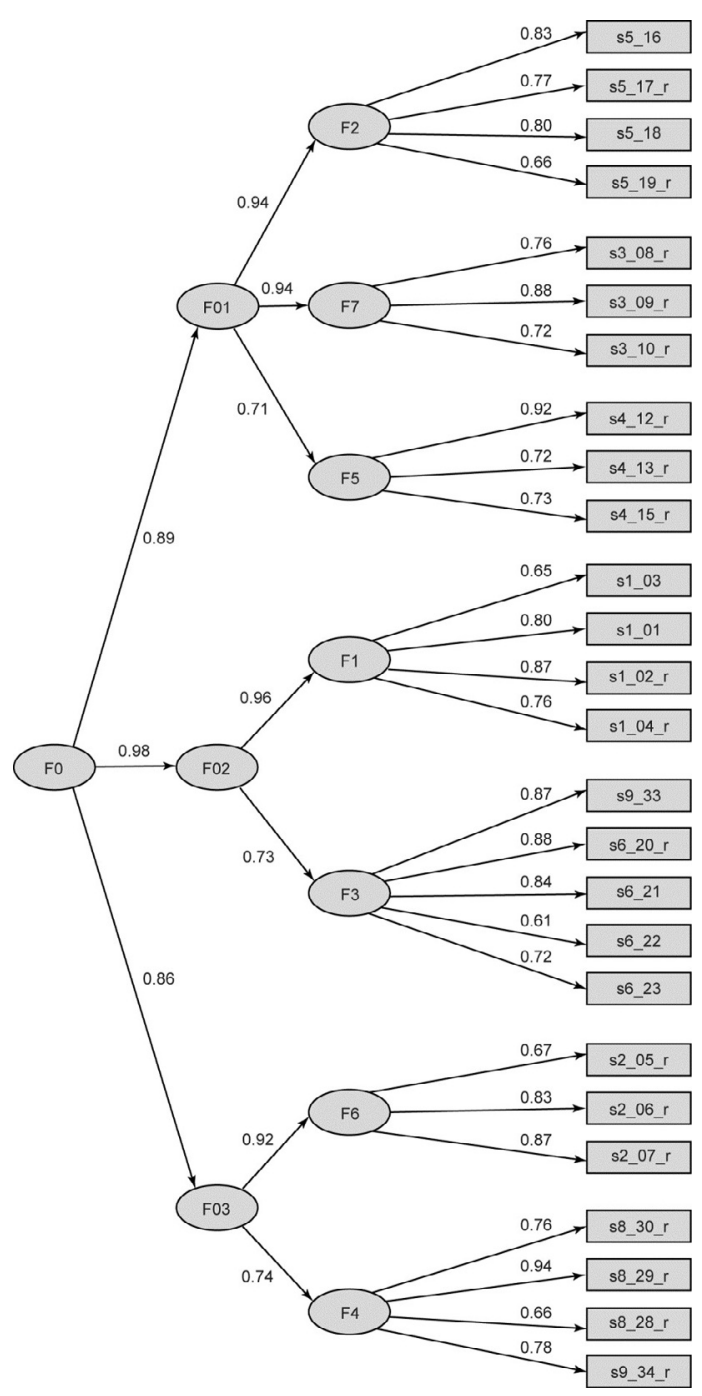

Примечание. F0 - общий фактор установки приверженности, F01-F03 - установки приверженности второго порядка (F01 - установка в отношении дискомфорта, F02 - установка в отношении угрозы COVID-19, F03 - установка рациональности в отношении пандемии); F1-F7 частные установки приверженности: F1 - просоциальность, F2 - толерантность к физическому дискомфорту, F3 - страх за себя и близких, F4 - антиконспирологическая установка, F5 - комфортность общения, F6 - принятие ограничений индивидуальной свободы, F7 - устойчивость самооценки. 
У лиц с высшим образованием в сравнении с лицами со среднеспециальным образованием более выражены принятие ограничений индивидуальной свободы и устойчивость самооценки (критерий Краскалла-Уоллеса, $p=0.004, p=0.017$ соответственно).

\section{Различия в установках приверженности в группах с различным соблюде- нием масочного режима}

Были выявлены значимые различия по всем шкалам установок между сравнивавшимися попарно группами респондентов, различавшихся приверженностью масочному режиму (критерий Манна-Уитни, различия по всем показателям достоверны на уровне $p \leqslant 0.05$ с учетом поправки Холма на множественные сравнения). Максимальная выраженность установок приверженности характерна для тех, кто соблюдает масочный режим всегда или почти всегда, минимальная - для не соблюдающих его никогда. Среднее положение занимает группа тех, кто соблюдает режим иногда.

Группа с неустойчивой приверженностью была разбита по мотивационным основаниям на непересекающиеся подгруппы респондентов, указавших, что они носят маски в следующих случаях:

- подгруппа $2 \mathrm{~A}$ «Ситуативно-рациональная ориентащия» (критерий включения - наличие ответа «если я считаю, что в данном месте высока вероятность заражения» или «если наблюдается рост заболеваемости») $(\mathrm{N}=152)$;

- подгруппа 2Б «Ориентация на большинство» (критерий включения наличие ответа «если я вижу, что в данной ситуации/месте большинство людей в масках») $(\mathrm{N}=47)$;

- подгруппа 2В «Ориентация на санкиии» (критерий включения - единственный ответ «если я знаю, что меня оштрафуют или откажут в обслуживании») $(\mathrm{N}=77)$.

В связи с тем что выбор мотивационных оснований был множественным, респонденты подгрупп 2А и 2Б могли указать, помимо главного основания, определявшего принадлежность к подгруппе, и другие основания. Так, в подгруппу «Ориентаиия на большинство» вошли те, кто также мог указать ориентацию на наказание; в подгруппу «Ситуативно-ращиональная ориентащия»те, кто также мог указать ориентацию на наказание либо на большинство.

Мы предполагали, что данные мотивационные основания будут дифференцировать респондентов по их установкам приверженности. А именно наиболее выраженные установки будут характерны для ситуативно-рациональной ориентации, предполагающей рефлексию рисков заражения в конкретных обстоятельствах. Наименее сопряженной с установками приверженности представляется ориентация на санкции, т.е. внешняя мотивация возможностью наказания. Ориентация на большинство представляется занимающей промежуточное положение, поскольку предполагает следование норме исходя из более поверхностных, чем оценка рисков, конформистских соображений. Этим предположениям соответствует картина изменения общего показателя установок в выделенных подгруппах респондентов, приведенная на рисунке 2. 
Рисунок 2

Общий показатель установок приверженности режиму ношения масок в группах/подгруппах респондентов, различающихся по соблюдению масочного режима и его мотивационным основаниям

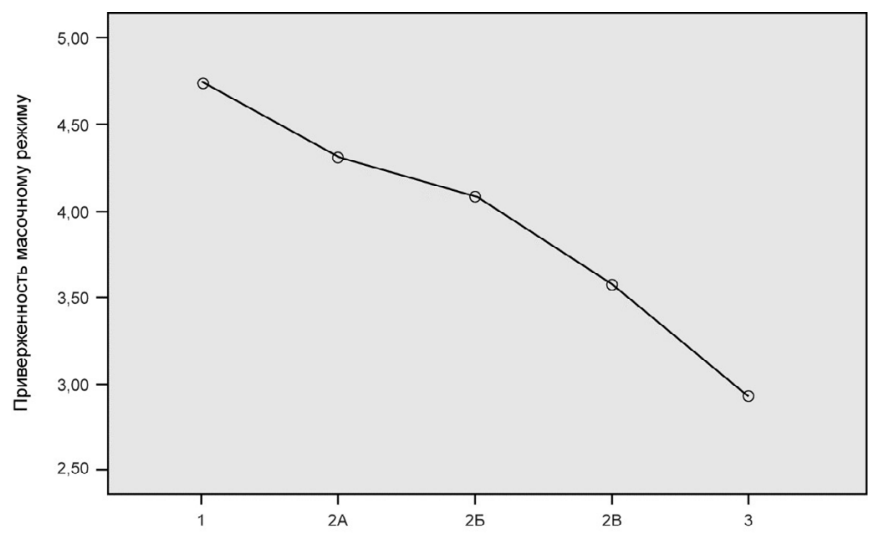

Примечание. 1 - группа приверженных, 2А, 2Б, 2В - подгруппы с неустойчивой приверженностью (2А - «Ситуативно-рациональная ориентация»; 2Б - «Ориентация на большинство», 2В - «Ориентация на санкции»), 3 - группа неприверженных.

Средние значения установок приверженности в группах и подгруппах приведены в таблице 5 .

Таблица 5

Средние значения показателей установок в отношении масочного режима в группах/подгруппах респондентов

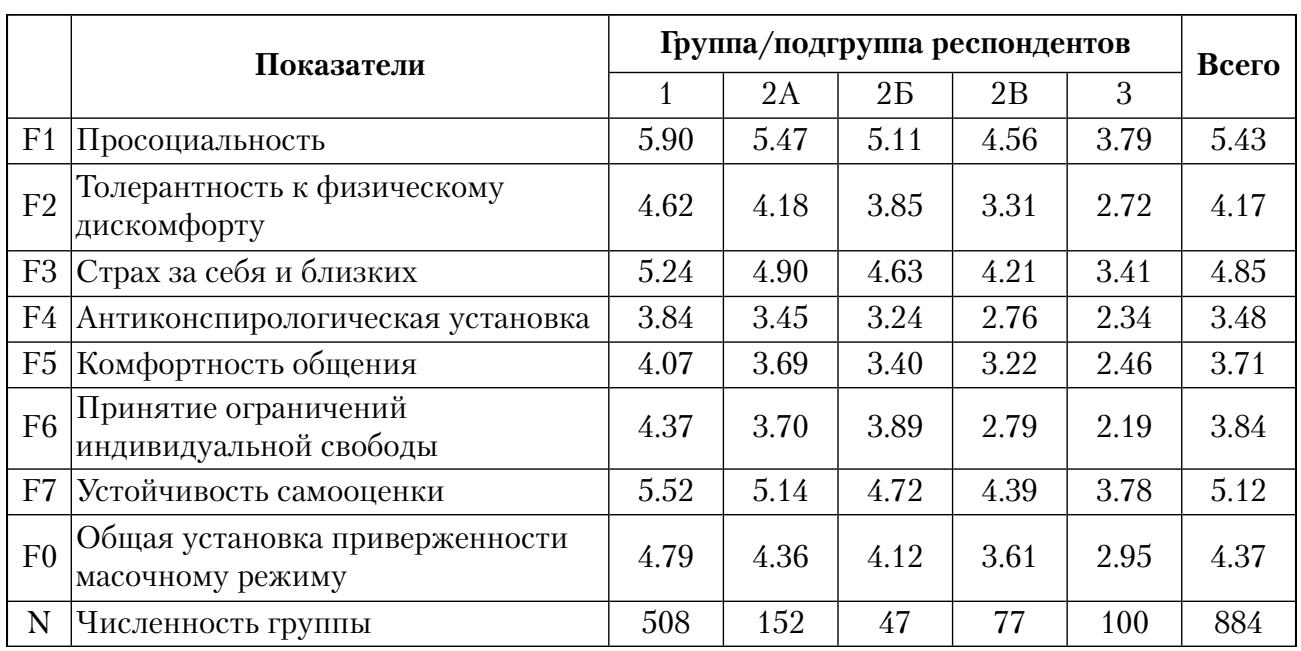

Примечание. 1 - группа приверженных; $2 \mathrm{~A}$ - подгруппа «Ситуативно-рациональная ориентация»; 2Б - подгруппа «Ориентация на большинство», 2В - подгруппа «Ориентация на санкции»; 3 - группа неприверженных. 
Для проверки гипотезы о различиях в установках в зависимости от мотивов соблюдения масочного режима было проведено попарное сравнение соседних подгрупп с применением поправки Холма на множественные сравнения. Были получены следующие результаты (см. таблицу 6):

1) группа 1 («Приверженные») имеет бо́льшую выраженность всех установок приверженности в сравнении с подгруппой 2 А («Ситуативно-рациональная ориентащия»);

2) подгруппа 2A («Ситуативно-ращиональная ориентаиия») и подгруппа 2Б («Ориентащия на большинство») не различаются в установках приверженности; подгруппа 2А отличается более высокой приверженностью по всем установкам от группы 2В («Ориентащия на санкции»);

Таблииа 6

Сравнение групповых средних рангов по критерию Манна-Уитни*

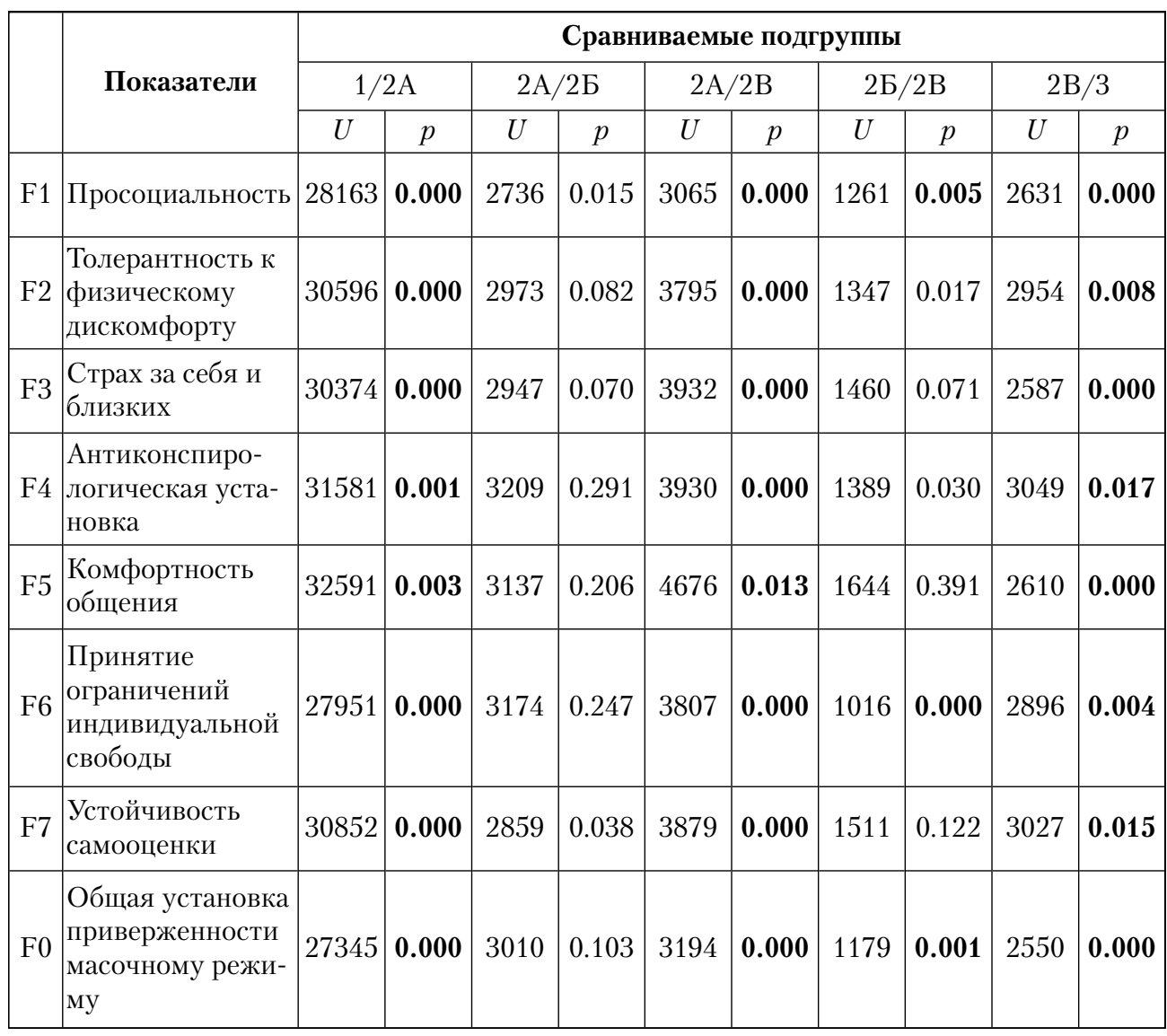

Примечание. ${ }^{*} U-$ величина критерия, $p$ - асимптотическая значимость (двусторонняя). Показатели значимости, соответствующие требованию $p<0.05$ после применения поправки Холма на множественную проверку гипотез, выделены жирным шрифтом. 
3) подгруппа 2Б («Ориентащия на большинство») отличается от подгруппы 2В («Ориентация на санкции») более выраженной просоциальностью и принятием ограничений индивидуальной свободы;

4) группа 3 («Неприверженные») отличается от подгруппы 2В («Ориентация на санкции») меньшей выраженностью всех установок приверженности масочному режиму.

Таким образом, можно говорить о плавном снижении установок приверженности в выделенных нами группах и подгруппах. Исключение составили те, кто носят маски по ситуации, и те, кто ориентируются на большинство: они не различаются между собой в установках приверженности.

\section{Обсуждение}

При оценке распределения российских респондентов по степени приверженности масочному режиму следует учитывать, что данное исследование было проведено в момент самого начала второй волны роста темпов заражения, пик которой пришелся на ноябрь и декабрь 2020 г. Именно в первую неделю октября недельное число выявленных случаев заражения COVID-19 в РФ впервые превысило 100 тысяч, а на второй неделе оказалось на 20\% выше, чем на первой ${ }^{1}$. При этом в сентябре 2020 г. отсутствовало ограничение передвижений, возобновилась очная работа образовательных учреждений, органы власти не анонсировали усиление ограничительных мер, подобных весеннему и летнему периоду пандемии 2020 г.

По-видимому, серьезность динамики заражения еще не была явной для большинства граждан, и этим можно объяснить сравнительно высокую долю респондентов с неустойчивой приверженностью (31.2\%) и сравнительно невысокую с высокой приверженностью (57.5\%). Подобное соотношение, например, было характерно для июня 2020 г. в США, но на фоне ухудшения эпидемиологической ситуации оно скорректировалось до 80-85\% высокой приверженности к августу и сохранялось таким вплоть до октября 2020 г. (Kramer, 2020; Whang, Elliot, 2020). Дополнительным фактором относительно большого разброса в соблюдении масочного режима, по-видимому, можно признать малую частоту непосредственного столкновения респондентов с COVID-19 и связанными с ним людскими потерями. Доля же противников масочного режима $-11.3 \%$ - сопоставима с данными стран Европы и Северной Америки; ее относительное постоянство и независимость от ситуативных факторов (темпов и масштаба заражения) подчеркивались в литературе (Taylor, Asmundson, 2021).

Связи социально-демографических факторов с уровнем приверженности российских респондентов масочному режиму сопоставимы с доступными нам данными опросов в США июля 2020 г. Женщины демонстрируют бо́льшую приверженность, чем мужчины; отсутствуют различия в связи с возрастом и образованием (Taylor, Asmundson, 2021; Kramer, 2020). Было засвидетельствовано (Сapraro,

1 Роспотребнадзор. Актуальная эпидемическая ситуация в России и в мире. https://www.rospotrebnadzor.ru/region/korono_virus/epid.php (Дата обращения: 21 апреля 2021 г.). 
Barcelo, 2020), что на уровне установок мужчины менее ориентированы на соблюдение масочного режима: в сравнении с женщинами они менее просоциальны, ассоциируют ношение масок с проявлением слабости, приуменьшают угрозу COVID-19 для себя и близких, менее толерантны к физическому дискомфорту.

Отсутствие связи приверженности с образованием и возрастом, несмотря на небольшие различия в установках подгрупп респондентов, выделенных по этим основаниям, объясняется, по-видимому, тем, что их субъективная оценка угрозы и восприятие информационных воздействий об ограничительных мерах сходны. Вопреки предположениям ни более высокий уровень рациональности, ассоциированный с образованием, ни бо́льшая воспринимаемая уязвимость пожилых людей перед угрозой заболевания не обеспечили более выраженное следование масочному режиму. Это подводит к предположению о существенной универсальности феноменологического отражения угрозы COVID-19, которое далее было изучено нами на материале установок к масочному режиму.

Наиболее важным результатом исследования является описание иерархической системы установок приверженности масочному режиму на основе изучения психологических потребностей человека в ситуации применения этой ограничительной меры. Был разработан опросник 7 частных установок приверженности: просоциальность, толерантность к физическому дискомфорту, страх за себя и близких, антиконспирологическая установка, комфортность общения, принятие ограничений индивидуальной свободы, устойчивость самооценки. Наилучшее соответствие данным показала иерархическая модель с общим фактором установки приверженности в вершине, тремя факторами установок второго порядка и семью факторами частных установок, заложенными в опросник.

Установки второго порядка охватывают три направления. Так, «дискомфорт в связи с ношением масок» отражает представления о физиологической, социально-коммуникативной и психологической «цене», которую «платит» человек за ношение маски. «Угроза COVID-19 для себя и других» объединяет переживание COVID-19 как серьезной персональной и социальной проблемы. «Рациональная оценка пандемии COVID-19» включает антиконспирологическую позицию и готовность к ограничению индивидуальной свободы в борьбе с угрозой.

Высокие корреляции между установками всех уровней свидетельствуют в пользу выраженной одномерности системы установок приверженности масочному режиму, т.е. о ее функционировании по принципу общего отношения к ограничительной мере (позитивного или негативного). Одномерность является косвенным признаком отсутствия рефлексии отдельных потребностей как независимых от общей оценки ограничительной меры. Например, маловероятны «когнитивно-дифференцированные» ответы респондентов, одновременно признающие высокий дискомфорт в связи с ношением масок и необходимость их носить в связи с просоциальными соображениями или сочетающие конспирологические убеждения и выраженный страх заболева- 
ния. Иначе говоря, субъективное отражение потребностей имеет результатом внутренне непротиворечивый сплав установок к соблюдению масочного режима, который в конечном итоге определяет поведение по принципу «сверху вниз» («top-down»). По-видимому, данный феномен можно рассматривать как проявление принципа необходимой когерентности в организации социальных представлений/установок. Например, сходное явление было выявлено при изучении представлений о морали А.В. Чистопольской: у религиозных участников в сравнении с атеистами первый фактор недифференцированной негативной оценки моральности поступков оказался более мощным (Чистопольская, 2010). При этом наши результаты свидетельствуют тем не менее о том, что все частные установки приверженности действительно дифференцируют респондентов по соблюдению масочного режима (3 уровня соблюдение всегда, иногда, никогда).

Целесообразно обсудить относительное значение отдельных установок приверженности масочному режиму в их общей системе. Мы делаем заключение об особо важной роли установки просоциальности, которая определялась как признание необходимости заботиться о здоровье других людей. Именно она в наибольшей степени предсказывалась общей установкой.

Все остальные частные установки, по нашим данным, являлись «равными среди прочих», успешно дифференцируя выборку по трем основным уровням приверженности. Так, мы не нашли подтверждения исключительной роли психологического сопротивления (psychological reactance) в приверженности масочному режиму, продемонстрированной в выборках США и Канады (Taylor, Asmundson, 2020). В нашей работе ему по смыслу соответствовала установка «принятие ограничений индивидуальной свободы», которая, хоть и имела некоторую вариативность в связи с образованием и возрастом респондентов, не дифференцировала их приверженность. Аналогично, факторы конспирологии и страха, активно обсуждаемые в литературе (Harper et al., 2021; Romer, Jamieson, 2020), не выделялись существенно в своих эффектах.

Мы выявили, что мотивационные основания неустойчивой приверженности по-разному корреспондируют с установками. А именно ориентация на санкции в сравнении с конформизмом ассоциируется с меньшей просоциальностью и большей нетерпимостью к ограничению индивидуальной свободы, а в сравнении с оцениванием ситуативных рисков заражения отличается меньшей выраженностью всех установок приверженности. При этом две мотивационные ориентации - оценка рисков и конформизм - оказались близки (неразличимы) в установках приверженности. Таким образом, при неустойчивой приверженности наблюдается скорее поляризация, чем более дробная дифференциация установок.

Результаты исследования в целом дают основания для ряда заключений, которые могут быть положены в основу рекомендаций в отношении мероприятий по повышению приверженности масочному режиму.

Во-первых, иерархический характер системы установок и их тесная взаимосвязь между собой предполагает, что постановка вопроса о том, какие именно информационные сообщения будут более эффективны, как это делается в 
некоторых исследованиях, не может иметь универсального ответа. Необходимо понимать, что любые убеждающие сообщения могут приводить к вариантам эффекта поляризации (Kuhn, Lao, 1996), т.е. к росту выраженности исходных убеждений, именно в связи с действием центростремительной силы организации установок в систему. Поэтому первична и оптимальна опора на принципы умеренности в экспрессии, разнообразия в содержании, систематичности в информационных воздействиях.

Во-вторых, наибольший интерес с точки зрения повышения приверженности представляют лица с неустойчивой приверженностью. Они не имеют столь поляризованных установок, как приверженные и неприверженные, и, вероятно, характеризуются большей гибкостью. Так как, по нашим данным, просоциальность в форме заботы о здоровье других в период пандемии в наибольшей степени отражает общую установку приверженности, информирование с опорой на просоциальность может быть наиболее эффективным. В рамках теории самодетерминации (Deci, Ryan, 2008) потребность в связи с другими людьми имеет два аспекта: ожидание от других понимания/заботы и потребность самому осуществлять заботу о других. Таким образом, в мотивирующих сообщениях (Martela et al., 2021) предлагается, с одной стороны, проявлять понимание и эмпатию в связи с переживанием трудностей и дискомфорта, с другой - делать акцент на общей идентичности и общей «беде» («мы все здесь в одной лодке»), апеллировать к потребности помогать другим людям.

В-третьих, у лиц с неустойчивым соблюдением масочного режима выявлены различия в установках приверженности в зависимости от мотивации к ношению масок. Наиболее конструктивный профиль имеют те, кто опирается на ситуативно-рациональные основания в решении, надевать ли маску. Вместе с тем эти люди все же отличаются по всем установкам от лиц с устойчивой приверженностью. Следует предположить, что индивиды с данным профилем рассматривают свое мнение о рисках как опору в принятии решений. В их адрес, вероятно, могут быть эффективны информационные послания, ориентированные на удовлетворение потребности в автономии: объяснение рациональности масочных ограничений и их научной обоснованности; подчеркивание значимости ответственности и индивидуального выбора, акцентирование на ценности масок в борьбе с COVID-19, а не на правилах.

В-четвертых, анализ установок приверженности индивидов из конформистской группы (ориентирующиеся на большинство либо на внешние санкции) показал, что они не отличаются от лиц с более рациональным поведением (ориентирующихся на ситуативный риск заражения). Таким образом, индивиды, ориентирующиеся на большинство, имеют относительно конструктивные установки приверженности. Они, вероятно, нечасто анализируют свое поведение в связи с масками, но и не являются противниками масок. Для этой аудитории будут эффективны информационные сообщения, исходящие от лиц, пользующихся популярностью и доверием большей части сообщества. Это позволит создать индивидам с конформистской установкой возможность для идентификации с человеком (людьми), которые привержены ограничениям. 
B-пятых, мы получили данные о том, что респонденты, ориентирующиеся на внешние ограничения (санкции либо отказ в обслуживании), имеют все же более конструктивные установки приверженности по сравнению с не соблюдающими режим ношения масок. Это свидетельствует о том, что для определенной группы лиц контролирующие послания эффективны и могут быть рассмотрены наряду с просоциальными посланиями и посланиями, акцентирующими автономию в принятии решений.

Ограничения данного исследования связаны прежде всего с тем, что приверженность рассматривалась только через призму индивидуальных установок. В следующей публикации планируется расширить набор факторов, определяющих приверженность масочному режиму. Кроме того, в данной выборке вероятно завышение доли приверженных режиму ношения масок по сравнению с российской популяцией в целом. Это связано с тем, что исследование было анонимным и на него могли откликаться люди, персонально затронутые этой темой. Также стоит учитывать, что исследование было проведено в самом начале второй волны COVID-19 в России, когда уровень заболеваемости повысился по сравнению с летним уровнем, но был еще далек от пиковых значений.

\section{Литература}

Маслоу, А. (2008). Мотивачия и личность. СПб.: Питер.

Нестик, Т. А., Дейнека, О. С., Максименко, А. А. (2020). Социально-психологические предпосылки веры в конспирологические теории происхождения COVID-19 и вовлеченность в сетевые коммуникации. Социальная психология и общество, 11(4), 87-104. https://doi.org/10.17759/sps.2020110407

Фрейд, 3. (2018). По ту сторону принщипа удовольствия. Ижевск: ERGO.

Чистопольская, А. В. (2010). Взаимосвязь представлений человека о морали и его принадлежности к религиозной группе. В кн. В. Ф. Спиридонов (ред.), Теоретические и прикладные проблемы психологии мышления: Сборник статей участников Всероссийской конферениии молодых ученых, посвященной памяти Карла Дункера (с. 141-149). М.: РГГУ.

Ссылки на зарубежные источники см. в разделе References.

\section{References}

Bish, A., \& Michie, S. (2010). Demographic and attitudinal determinants of protective behaviours during a pandemic: A review. British Journal of Health Psychology, 15, 797-824. https://doi.org/10.1348/135910710X485826

Capraro, V., \& Barcelo, H. (2020). The effect of messaging and gender on intentions to wear a mask covering to slow down COVID-19 transmission. Journal of Behavioral Economics for Policy, 4(COVID 19 Special Issue 2), 45-55. https://sabeconomics.org/wordpress/wpcontent/uploads/JBEP-4-S2-5.pdf

Chistopolskaya, A. V. (2010). Vzaimosvyaz' predstavlenii cheloveka o morali i ego prinadlezhnosti k religioznoi gruppe [The relationships between one's moral beliefs and their belonging to a religious group]. In V. F. Spiridonov (Ed.), Teoreticheskie i prikladnye problemy psikhologii myshleniya: Sbornik 
statei uchastnikov Vserossiiskoi konferentsii molodykh uchenykh, posvyashchennoi pamyati Karla Dunkera [Theoretical and applied issues of psychology of thinking: Papers from the All-Russian conference of young scientists in memory of Karl Duncker] (pp. 141-149). Moscow: RGGU.

Chu, D. K., Akl, E. A., Duda, S., Solo, K., Yaacoub, S., Schünemann, H. J., \& Urgent, C.-S. (2020). Physical distancing, face masks, and eye protection to prevent person-to-person transmission of SARS-CoV-2 and COVID-19: a systematic review and meta-analysis. Lancet, 395, 1973-1987. https://doi.org/10.1016/S0140-6736(20)31142-9

Deci, E. L., \& Ryan, R. M. (2008). Self-determination theory: A macrotheory of human motivation, development, and health. Canadian Psychology/Psychologie canadienne, 49(3), 182-185. https://doi.org/10.1037/a0012801

Eikenberry, S. E., Mancuso, M., Iboi, E., Phan, T., Eikenberry, K., Kuang, Y., Kostelich, E., \& Gumel, A. B. (2020). To mask or not to mask: Modeling the potential for face mask use by the general public to curtail the COVID-19 pandemic. Infectious Disease Modelling, 5, 293-308. https://doi.org/10.1016/j.idm.2020.04.001

Freud, S. (2018). Po tu storonu principa udovol'stviya [Beyond the pleasure principle]. Izhevsk: ERGO. (Original work published 1920 in German)

Goldsmith, A. (2005). Police reform and the problem of trust. Theoretical Criminology, 9(4), 443-470. https://doi.org/10.1177/1362480605057727

Harper, C. A., Satchell, L. P., Fido, D., \& Latzman, R. D. (2021). Functional fear predicts public health compliance in the COVID-19 pandemic. International Journal of Mental Health and Addiction, 19, 1875-1888. https://doi.org/10.1007/s11469-020-00281-5

Kramer, S. (2020, August 27). More Americans say they are regularly wearing masks in stores and other businesses. https://www.pewresearch.org/fact-tank/2020/08/27/more-americans-saythey-are-regularly-wearing-masks-in-stores-and-other-businesses/

Kuhn, D., \& Lao, J. (1996). Effects of evidence on attitudes: Is polarization the norm? Psychological Science, 7(2), 115-120. https://doi.org/10.1111/j.1467-9280.1996.tb00340.x

Lau, J. T. F., Griffiths, S., Choi, K., \& Lin, C. (2010). Prevalence of preventive behaviors and associated factors during early phase of the H1N1 influenza epidemic. American Journal of Infection Control, 38(5), 374-380. https://doi.org/10.1016/j.ajic.2010.03.002

Martela, F., Hankonen, N., Ryan, R. M., \& Vansteenkiste, M. (2021). Motivating voluntary compliance to behavioural restrictions: Self-determination theory-based checklist of principles for COVID-19 and other emergency communications. European Review of Social Psychology. https://doi.org/10.1080/10463283.2020.1857082

Martínez, D., Parilli, C., Scartascini, C., \& Simpser, A. (2021). Let's (not) get together! The role of social norms on social distancing during COVID-19. PLoS ONE, 16(3), Article e0247454. https://doi.org/10.1371/journal.pone.0247454

Maslow, A. (2008). Motivatsiya i lichnost' [Motivation and personality]. Saint Petersburg: Piter. (Original work published 1954)

Murphy, K. (2016). Turning defiance into compliance with procedural justice: Understanding reactions to regulatory encounters through motivational posturing. Regulation and Governance, 10, 93-109. https://doi.org/10.1111/rego.12073

Nagin, D. (2013). Deterrence in the twenty-first century. Crime and Justice, 42(1), 199-263. https://doi.org/10.1086/670398

Nestik, T. A., Deyneka, O. S., \& Maksimenko, A. A. (2020). Socio-psychological predictors of belief in conspiracy theories of the origin of COVID-19 and involvement in social media. Sotsialnaya 
Psikhologiya i Obshchestvo [Social Psychology and Society], 11(4), 87-104. https:/doi.org/ 10.17759/sps.2020110407 (in Russian)

Ong, J. J. Y., Bharatendu, C., Goh, Y., Tang, J. Z. Y., Sooi, K. W. X., Tan, Y. L., Tan, B. Y. Q., Teoh, H., Ong, S. T., Allen, D. M., \& Sharma, V. K. (2020). Headaches associated with personal protective equipment - A cross-sectional study among frontline healthcare workers during COVID-19. Headache. The Journal of Head and Face Pain, 60(5), 864-877. https://doi.org/10.1111/head.13811

Pfattheicher, S., Nockur, L., Böhm, R., Sassenrath, C., \& Petersen, M. B. (2020). The emotional path to action: Empathy promotes physical distancing and wearing of face masks during the COVID-19 pandemic. Psychological Science, 31(11), 1363-1373. https://doi.org/10.1177/0956797620964422

Pratt, T., Cullen, F., Blevins, K., Daigle, L., \& Madensen, T. (2008). The empirical status of deterrence theory: A meta-analysis. In F. Cullen, J. Vright, \& K. Blevins (Eds.), Taking stock: The status of criminological theory (pp. 367-396). Transaction Publishers.

Prentice, M., Halusic, M., \& Sheldon, K. M. (2014). Integrating theories of psychological needs-as-requirements and integrating theories of psychological needs-as-requirements and psychological needs-as-motives: A two process model. Social and Personality Psychology, 8(2), 73-85. https://doi.org/10.1111/spc3.12088

Roberge, R. J., Bayer, E., Powell, J. B., Coca, A., Roberage, M. R., \& Benson, S. M. (2010a). Effect of exhaled moisture on breathing resistance of N95 filtering facepiece respirators. The Annals of Occupational Hygiene, 54(6), 671-677. https://doi.org/10.1093/annhyg/meq042

Roberge, R. J., Coca, A., Williams, W. J., Powell, J. B., \& Palmiero, A. J. (2010b). Physiological impact of the N95 filtering facepiece respirator on healthcare workers. Respiratory Care, 55(5), 569-577.

Romer, D., \& Jamieson, K. H. (2020). Conspiracy theories as barriers to controlling the spread of COVID-19 in the U.S. Social Science \& Medicine, 263, Article 113356. https://doi.org/ 10.1016/j.socscimed.2020.113356

Rosenberg, B. D., \& Siegel, J. T. (2018). A 50-year review of psychological reactance theory: Do not read this article. Motivation Science, 4(4), 281-300. https://doi.org/10.1037/mot0000091

Ryan, R. M., \& Deci, E. L. (2000). Self-determination theory and the facilitation of intrinsic motivation, social development, and well-being. American Psychologist, 55(1), 68-78. https://doi.org/10.1037/0003-066X.55.1.68

Scerri, M., \& Grech, V. (2020). To wear or not to wear? Adherence to face mask use during the COVID-19 and Spanish influenza pandemics. Early Human Development, Article 105253. Withdrawn article in press. https://doi.org/10.1016/j.earlhumdev.2020.105253

Scheid, J. L., Lupien, S. P., Ford, G. S., \& West, S. L. (2020). Commentary: Physiological and psychological impact of face mask usage during the COVID-19 pandemic. International Journal of Environmental Research and Public Health, 17(18), Article 6655. https://doi.org/10.3390/ ijerph17186655

Tang, C. S., \& Wong, C., (2004). Factors influencing the wearing of facemasks to prevent the severe acute respiratory syndrome among adult Chinese in Hong Kong. Preventive Medicine, 39, 11871193. https://doi.org/10.1016/j.ypmed.2004.04.032

Taylor, S., \& Asmundson, G. J. G. (2021). Negative attitudes about facemasks during the COVID-19 pandemic: The dual importance of perceived ineffectiveness and psychological reactance. PLoS ONE, 16(2), Article e0246317. https://doi. org/10.1371/journal.pone.0246317

Tyler, T. (2006). Why people obey the law. Princeton University Press.

Whang, O., \& Elliott, K. (2020, October 5). Poll finds more Americans than ever think we should wear masks. National Geographic. https://www.nationalgeographic.com/history/article/poll-increasing-bipartisan-majority-americans-support-mask-wearing 